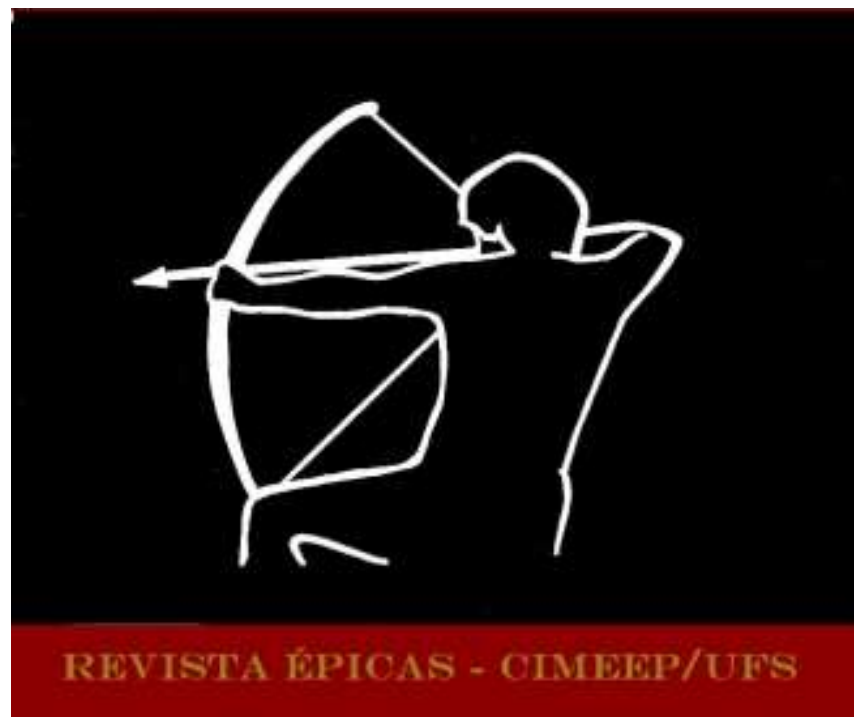

RIBEIRO, Maria Aparecida.Maria Valéria Rezende e o seu Vasto mundo: uma transfiguração do épico?. In: Revista Épicas. Ano 4, N. 8, Dez 2020, p. 88-100. ISSN 2527-080-X. DOI: http://dx.doi.org/10.47044/2527-080X.2020v8.88100

\title{
MARIA VALÉRIA REZENDE E O SEU VASTO MUNDO: UMA TRANSFIGURAÇÃO DO ÉPICO?
}

\section{MARIA VALÉRIA REZENDE AND HER VASTO MUNDO:: AN EPIC TRANSFIGURATION?}

Maria Aparecida Ribeiro

CLP/Universidade de Coimbra

Resumo: Vasto Mundo, da autoria de Maria Valéria Rezende, composto por vários episódios passados na fictícia povoação paraibana de Farinhada, foi classificado pelo apresentador e pela editora como um livro de contos. No entanto, tem uma unidade narrativa. Além disso, possui elementos que the conferem um sabor épico e colocam o livro na esteira das transformações sofridas pela épica brasileira.

Palavras-chave: épica; Maria Valéria Rezende; Literatura Brasileira.

Abstract: Vasto Mundo, written by Maria Valéria Rezende, is composed of several past episodes in Farinhada, a fictitious settlement in Paraíba, and was classified by the presenter and by the publisher as a storybook. However, it has a narrative unity. In addition, it has elements that grant it an epic flavor and places the book in the track of the transformations undergone by the Brazilian epic tradition.

Keywords: epic; Maria Valéria Rezende; Brazilian literature.

\section{Introdução}

Ao escrever Vasto Mundo, Maria Valéria Rezende compôs vários episódios, em que as personagens centrais são os elementos de um coletivo. Trata-se de uma narrativa única, mas, ao 
fazer a apresentação do texto, Frei Betto pensou tratar-se de um livro de contos, subgênero com que a editora acabou por classificar o livro.

Não se trata disso, e há ainda um sabor épico, que é o que se pretende localizar e discutir. Como lembra Maria Helena da Rocha Pereira, Aristóteles, distinguindo a epopeia da tragédia, escreveu em sua Poética que a aquela é "uma imitação em verso de homens superiores" e tem "um metro único", além de ser "uma narrativa" e ter "um âmbito cronológico ilimitado" (PEREIRA, 2014, p.311). Além disso, a estudiosa lembra também que o Prof. Bruno Snell, "transcendendo a delimitação formal de Aristóteles, propôs uma tese que ficou célebre": não é o herói épico, mas os deuses que tomam as decisões ou o ajudam a decidir (Cf. PEREIRA, 2014, p. 312). Melhor dizendo: "o heroi épico, nos grandes momentos da sua vida, está condicionado pela decisão divina, por um impulso vindo do alto." (Cf. PEREIRA, 2014, p. 316).

Outro elemento importante da epopeia clássica para o qual Rocha Pereira chama a atenção são os valores éticos que nelas aparecem e norteavam a sociedade da época em que foram escritas (Cf. PEREIRA, 2014, p. 311).

No entanto, é sabido que, ao longo dos tempos, os valores éticos se foram modificando. Mas não só eles: a própria epopeia e o conceito de épico, palavra hoje usada pela juventude brasileira, por exemplo, para qualquer coisa que considere notável, grandiose ou que demande muito esforço: um jogo de futebol pode ser épico, assim como uma festa de casamento ou uma viagem com percalços. Exatamente por essa mudança nos valoresétivos, mas não só, torna-se necessário tecer algumas considerações sobre as mudanças sofridas pela epopeia no Brasil.

\section{Do poema ao romance (e não só)}

\subsection{No Brasil-Colônia}

Desde os tempos do Brasil-Colônia - e porque a literatura do periodo tinha forte motivação clássica - surgiram no Brasil várias epopeias. Por exemplo: o De Gestis Mendi de Saa, do Padre José de Anchieta; o Caramuru, de Santa Rita Durão; O Uraguai, de Basílio da Gama; Vila Rica, de Cláudio Manuel da Costa. E como a epopeia imita homens - e homens superiores esses quatro textos, tratando da conquista da terra, mostraram portugueses vencendo índios. (Diga-se que Anchieta, Durão e Cláudio, embora não nascidos em Portugal, aí estudaram, o que 
Ihes formata, por assim dizer, a visão dos fatos. Já Basílio da Gama, que for a aluno dos jesuítas no Rio de Janeiro, talvez para se livrar da deportação que lhe impusera o Marquês de Pombal, passa a dedicar-lhe e à sua família uma série de poemas).

E como o herói épico, diferente do herói trágico, não decide, mas, sim, os deuses (ou ele próprio mas a conselho das divindades), a epopeia escrita por cristãos, em tempos de conquista da terra brasileira, colocava Deus a auxiliar os portugueses. Se no canto I da Ilíada, quando Aquiles vai desembainhar a espada contra Agaménon, Atena desce do Olimpo e o aconselha a dominarse, Anchieta narrador não poderia esquecer a sua condição, que se reflete também na sua condição de personagem: os mínimos pormenores revelam um homem profundamente cristão sob a pele do humanista. Assim é que, apesar do título dado à epopeia e do tratamento conferido à figura do Governador, propõe "celebrar em verso" as "magnas empresas" de Cristo Rei, das quais destaca a cristianização dos índios, "aurora por entre a escuridão das regiões brasileiras". Mem de Sá, era, assim, um instrumento de Deus, por ele enviado para que "vingasse os crimes nefandos [...] banisse as discórdias, freiasse o assassínio [...], acabasse com as guerras horrendas, abrandasse os peitos ferozes" (Cf. DG, I, p. 112-114 e p. 150-153). O que se tem, portanto, de ponta a ponta do poema, são os feitos de Mem de Sá, sempre inspirados por Deus e tendo em vista a mudança de hábitos do gentio. A antropofagia, a poligamia, a embriaguez com o cauim, que o olhar cristão de Anchieta condena a cada passo, vão sendo deixados, seja por imposição do Governador, seja por uma conversão operada. O espírito de cruzada informa o narrador do poema nas descrições e comentários e inspira o sujeito poético no louvor a Cristo, rei do Universo, da história humana e das almas.

Em função do seu objetivo, o poeta detém o seu foco no aspecto moral dos índios e dos heróis. Daí que todos os momentos do De Gestis sejam dedicados a mostrar como Mem de Sá levou ao gentio o nome de Cristo. O próprio trabalho dos jesuítas acaba por ser consequência dessa primeira imposição de novos costumes, feita à força. É Mem de Sá quem dá "força de lei civil" aos mandamentos divinos.

A cultura indígena é desqualificada: todas as práticas indígenas estão, para o jesuíta, associadas ao demônio. A vitória de Mem de Sá é uma vitória contra o Mal, razão por que Anchieta, apesar de pintar fisicamente o Governador, privilegia no seu retrato o aspecto 
espiritual: é o desprezo pelas glórias humanas e o amor de Deus que ele aconselha ao filho Fernão; é a confiança em Deus que demonstra quando ordena o aldeamento dos índios e a sua mudança de costumes contra as murmurações da população. Desse perfil que vem desenhado desde o princípio do poema resulta a invocação de Mem de Sá a Cristo, pedindo-Lhe auxílio, quando a falta de pólvora entre os portugueses prenuncia a vitória dos franceses e a possibilidade de o Seu nome vir a ser alvo da zombaria dos hereges.

No De Gestis, do princípio ao fim, os feitos de Mem de Sá são feitos de Deus e ele é instrumento da salvação dos índios, perdidos em guerras entre si, perdidos em meio aos hereges franceses. Sua dureza para com os índios é uma forma de luta por Cristo. Anchieta, leitor de Ovídio, de Salústio e principalmente de Virgílio é, sobretudo, leitor das Sagradas Escrituras e, mais que tudo, ele, sim, um soldado de Cristo.

Também no Caramuru - que Frei José de Santa Rita Durão escreveu em 1781, na cidade de Coimbra, em cuja universidade estudou e foi professor -, Diogo Álvares Correia, o protagonista, é uma espécie de instrumento de Deus. Embora o Criador não intervenha diretamente, é o espírito cristão do português Diogo que lhe proporciona dominar as terras baianas, ajudando o pai da índia Paraguaçu a vencer a tribo inimiga, convertendo-o e à filha, com quem se casa dentro dos preceitos cristãos. Termina essa conversão-conquista pelo oferecimento que Paraguaçu faz das terras brasileiras ao Rei de Portugal.

Já n’O Uraguai (1769), Basílio da Gama inverte essa situação: surgem invectivas contra a cobiça portuguesa (e não só) pela boca de um herói índio, Cacambo: “Gentes de Europa, nunca vos trouxera / O mar e o vento a nós" (II, 171-174). No poema de Basílio da Gama, ainda em moldes clássicos, o heroísmo é dos índios e o Cristianismo se faz representar por maus padres e maus cristãos.

Em Vila Rica, concluída em 1773, mas publicada na íntegra postumamente, em 1839, o mineiro Cláudio Manuel da Costa, seu autor, mostra que os assuntos e moldes da epopeia no Brasil começam a modificar-se. O poema tem por objetivo celebrar a descoberta do ouro e a fundação de cidades; é o laudes urbium, ou elogio das cidades, de tradição clássica, retomada pelos humanistas europeus, nomeadamente os portugueses. E, se o texto se inicia com uma carta-dedicatória ao Conde de Bobadela e louva os feitos de Gomes Freire de Andrada, Cláudio 
valoriza a paisagem pátria - ainda não o Brasil, mas Minas Gerais, onde nasceu. É o "amor da pátria" (COSTA, 1996, p. 359), que o leva a escrever. Além da natureza fértil e opulenta, da majestade da paisagem, tópicos dos poemas barrocos anteriormente citados, o poema também inclui a figura do índio. Se a feitiçaria e o canibalismo estão entre seus costumes, estes não são mostrados como frequentes nem tão-pouco condenados, como no De Gestis. Também o fato de índios serem prisioneiros de índios surge no poema. A paixão entre um branco (Garcia) e uma índia (Aurora), como no Caramuru e n'O Uraguay, será igualmente um tópico abordado, embora Cláudio Manuel da Costa não Ihe dê maior destaque. E se o próprio autor duvida que tenha escrito um poema épico ${ }^{1}$, talvez o longo fundamento histórico de que se vale seja o início de um caminho que o Romantismo brasileiro irá percorrer.

\subsection{No Brasil independente e romântico}

Vários serão os poemas épicos ou de cariz épico durante o período romântico brasileiro. Tratados em A Epopeia em Questão: debates sobre a poesia épica no século XIX (FRIEDLIN; NUNES \& ZILBERMAN, 2020, p. 144-216), é de distinguir a mudança proposta e realizada por José de Alencar (cf. RIBEIRO, 2020, p. 144-172) que, com Iracema, concretiza o que propõe nas Cartas escritas a Gonçalves de Magalhães criticando o poema A Confederação dos Tamoios, da autoria deste. Alencar escreve em prosa esse texto de 1865, mas mantém nele características do poema épico, como a ordo artifilcialis, o início in ultimas res, os epítetos, os símiles, a construção das personagens como homens superiores. Como inovação de ponto de vista, faz desaparecer as guerras entre índios e portugueses durante a conquista da terra, transformando-a em coisa natural. Observe-se a frase de Martim quando vê Iracema pela primeira vez: " - Venho de longe, filha das florestas. Venho das terras que teus irmãos já possuíram e hoje têm os meus." (ALENCAR, 1994, p. 41); observe-se também que o nascimento do primeiro brasileiro surge não como um ato de violência, mas como ato de amor, pois Martim possui Iracema durante um sonho

\footnotetext{
1 “Não é meu intento sustentar que eu tenho produzido ao Mundo um Poema com caráter de épico; sei que esta felicidade não conseguiram até ao presente aqueles homens a quem a Fama celebra laureados na Grécia, na Itália, em Inglaterra, em França e nas Espanhas. Todos se expuseram à censura dos críticos, e todos são arguidos de algum erro ou defeitos; a razão pode ser a que assina um bom Autor: inventaram-se leis aonde as não havia. Mas dou-te, que eu não te ofereça mais que uma composição em metro, para fazer ver o distinto merecimento de um General que tão prudentemente pacificou um povo rebelde, que segurou a Real Autoridade e que estabeleceu e firmou, entre as diferentes emulações de uns e outros Vassalos desunidos, os interesses que se deviam aos Soberanos Príncipes de Portugal." (COSTA, 1996: 359)
} 
despoletado pelo elixir que a índia lhe dera. E repare-se que, em função desses apagamentos, a substituição das crenças, da língua e do nome se faz como que naturalmente: Poti ajoelha-se "aos pés do dagrado lenho", trocando de religião, língua e nome, para que nada mais o "separasse de seu irmão branco", pois tinham "um só coração" (ALENCAR, 1994: 96); o soar do bronze faz-se ouvir onde outrora "rugia o maracá" (ALENCAR, 1994: 96). Note-se ainda a frase final do Narrador, depois de todas essas mudanças e da morte de Iracema, quando a jandaia não canta mais o nome da filha de Araquém: "Tudo passa sobre a terra" (ALENCAR, 1994: 96 ). Somente no nome do filho da formosa índia e do conquistador português, do mestiço, do primeiro brasileiro, fica o sinal da fratura: afinal, Moacir significa filho da dor.

Outro texto épico a destacar, ainda no século XiX, mas já nos últimos momentos do Romantismo, é O Guesa de Joaquim de Sousândrade, cuja primeira edição Luísa Lobo acredita ser de 1884 (cf. LOBO, 2020, p. 286), embora seu autor afirme no prefácio (Memorabilia) da primeira edição (1876) que o poema (no caso, com o título de Guesa Errante) nada tem de épico e que é, antes, uma narrativa (cf. SOUSÂNDRADE, 2003, p. 484), o que é visto como uma influência das leituras de Platão (LOBO, 2020, p. 288-290), que volta a aparecer na “Memorabilia" da edição de 1877, porque o poeta "nega a aparência, a imitação, conforme expõe Platão no Livro 10 da República" (LOBO, 2020, p. 296).

Sousândrade, embora adote a temática heroica de Homero na Odisseia, concebe um texto que se afasta da épica homérica tradicional: usa versos brancos, rimas cruzadas e emparelhadas e retoma a tradição cristã de Dante, Milton, Espronceda, entre outros. Por outro lado, apesar de utilizar os versos decassílabos de Os Lusíadas e de até transportar para São Luís a "Ilha dos Amores" (ilhas imaginárias também se fazem presentes na Odisseia), nega Camões, que identifica com a monarquia portuguesa e o seu colonialismo. O mais importante, porém, para o que aqui se vem expondo, é que o poeta não elege personagens os índios do Brasil e não fala de suas lutas com os portugueses pela posse da terra, embora continue a falar de lutas entre autóctones e alóctones, na linha de Gonçlves Dias (embora este colque como opositores portugueses e í. O Guesa é um indígena muísca colombiano, o que amplia o indianismo do Romantismo brasileiro para um indianismo sul-americano. Além disso, Sousândrade foge ao modelo bélico da epopeia clássica e cria uma obra épica híbrida. 


\subsection{No século $X X$}

O princípio do século XX no Brasil é marcado pelo Modernismo, experimentando a epopeia estruturas inovadoras, ritmos diferentes, e a valorização da dimensão mítica da matéria épica, como se pode observar em Martim Cererê (1928), de Cassiano Ricardo; Cobra Norato (1931), de Raul Bopp, e ainda, nos ans 50, na Invenção de Orfeu (1952) de Jorge de Lima, e no Romanceiro da Inconfidência (1953) de Cecília Meireles.

Já num ciclo pós-moderno, o relato surge centrado ainda na dimensão mítica e desconstrutiva da matéria épica, mas a experiência de mundo é feita por uma vivência subjetiva do real histórico. O herói épico é despersonalizado e historicamente indefinido tornando-se um "eu" impessoalizado em busca de identidade, o que implica que o simples fato de viver seja entendido como um ato heroico. Nesse caso, estão o Poema Sujo (1976) de Ferreira Gullar e $A$ Grande Fala do Índio Guarani Perdido na História e Outras Derrotas (1976) de Affonso Romano de Sant'Anna.

Chame-se ainda a atenção para um texto escrito em 1960, mas só publicado em 1983: Os Heróis, de César Leal. São inscrições murais, poemas integrados no caráter da poesia épica, estudados por Hegel, juntamente com gnomos e epitáfios. Como diz o próprio autor, nessas inscrições murais que compõem o livro, "as personagens históricas, olhando o presente, contam algo do seu passado. Quase todos figuram em murais ou monumentos"'” (cf. LEAL, 1983, p. [9]), o que, certamente, Ihes dá a dimensão heroica. Mas no livro há um texto que, pela extensão, impossibilitadora de sua gravação em monumento, coluna, tijolo ou móvel, acaba por ser, segundo César Leal, um poema épico: são os quarenta e nove versos consagrados a Antônio Conselheiro.

\subsection{No século XXI: Vasto Mundo e o sabor épico}

No dealbar do século XXI, surge-nos Vasto Mundo (2001). Publicado pela editora Beca, é um livro com dezoito histórias que tem personagens em comum e cujo espaço é o povoado de Farinhada, no interior da Paraíba. Ao lê-lo, sentimos nele um sabor épico. E por quê? 
Embora Vasto Mundo não apresente as partes constituintes da epopeia (proposição, invocação, dedicatória), é possível ver em sua epígrafe uma espécie de proposição: “Amanhã é que ia ser mesmo a festa, a missa o todo do povo, o dia inteiro. Dião de dia!" (REZENDE, 2015, p. [9]). Tirada de Corpo de Baile, de Guimarães Rosa, mais precisamente de "Uma estória de amor (Festa de Manuelzão)", ela parece anunciar, como no conto, a festa como trabalho de todos, como a anulação da fronteira pobre/rico, como a irmanação, reunião, congraçamento. E este anúncio parece ser o que Maria Valéria, freira da Congregação da Cônegas de Santo Agostinho, pretende difundir com sua narrativa: a Teologia da Libertação.

Como nas epopeias, há, em Vasto Mundo, um Narrador que, no caso, identifica-se, como o próprio chão da terra, o chão de Farinhada, que divide a narrativa em três grandes momentos - "Voz do Chão I, II e III" - como se de três grandes cantos se tratasse. Cada um desses cantos é formado por episódios, entre os quais as personagens transitam; principais num, secundárias noutro, elas conferem ao texto uma espécie de unidade, até porque, nesses três momentos, são narradas pequenas e grandes lutas, individuais e coletivas. O primeiro momento, Voz o Chão I, também apresenta uma epígrafe: "Tantos pisam este chão que ele talvez um dia se humanize". Tirada de "Contemplação no banco", poema incluído por Carlos Drummond de Andrade em Claro Enigma, ela traz o mesmo espírito de luta, a mesma flor "calcárea, sanguínea", o mesmo "arcoíris" que aí se elabora, embora, ao reencenar o gesto de "A flor e a náusea" (de A Rosa do Povo), deixe de conter a utopia socialista que lhe dava sustentação.

As dezoito histórias narradas por Voz do Chão I, II e III nada mais são que dezoito episódios de uma narrativa maior que mostra a luta do povo de Farinhada: a luta pela posse da terra. Presente em quase todas as epopeias brasileiras (mas não só) até o século XIX (somente Alencar apaga esse dado, como já se viu, interessado em que está em falar da origem do brasileiro e mostrá-la como um ato de amor), ela volta a surgir. Do princípio ao fim, os despossuídos do lugar (que são muitos) enfrentam, em surdina ou com clamor, os poderosos (praticamente reduzidos a um grande senhor, o latifundiário e político Assis Tenório, curiosa combinação de nomes que evoca os de dois poderosos nordestinos - Assis Chateaubriand, paraibano, e Tenório Cavalcante, alagoano - embora surjam também outros representantes do poder - o Bispo e os políticos). 
A luta entre Assis Tenório e o povo de Farinhada é, na realidade o fio condutor da narrativa. A todo momento, Tenório impede, trama, despropria, cobra dividendos, tenta amendrontar:

Enquanto o velho Elpídio Tenório vivia, havia roçado para todo mundo que quisesse. [...] Quando o velho morreu e Assis voltou do Recife para tomar posse das terras, todo enfatuado de estudos e modernices, foi aquela desgraceira: botou quase todos para fora, só queria mandar plantar capim e criar gado. (REZENDE, 2015, p. 85)

Pelo contraste com o que faz D. Eulália, mulher de Assis Tenório, durante a doença que o acomete (Cf. "O tempo em que D. Eulália foi feliz", REZENDE, 2015, p. 69-81), ficam-se a saber os tipos de opressão a que ele sujeitava o povo de Farinhada: ela "não aperreou, não achacou, não castigou, não espoliou, não proibiu, não cobrou, não sujeitou, não humilhou, não ameaçou" (REZENDE, 2015, p. 76), o que significa que Tenório aperreava, castigava, espoliava, proibia, cobrava, sujeitava, humilhava, ameaçava.

A oposição entre Assis Tenório e o povo de Farinhada se faz sentir até mesmo no pastoril. Essa festa anual para os inconformados e até para os vencidos era a ocasião de gritar a plenos pulmões, sem risco imediato, o protesto por quanta injustiça e sofrimenro houvesse, de manifestar a esperançosa vitória, embora o azul, já se sabia, ganhasse sempre porque era o lado onde estavam o dinheiro e todos os xexeléus do poder.

Aquelas disputas fingidas entre o azul e o ecarnado, aquiem farinhada, são bem mais que uma rivalidade fingida, criada na hora da festa pela preferência por uma pastora, para causar despeito a outra ou porque um desafeto qualquer trazia uma fita contrária. Jamais ninguém o disse abertamente, porque toda a gente sabe muito bem que o azul era de Assis Tenório e o o encarnado era de Pedro do Antonino. Não que o sapateiro jamais tivssse tomado a frente de nads nem se metido na política de Farinhada, mas, desde a revelação de sua história, tornara-se o símbolo da resistência surda de muitos pobres de Farinhada os desmandos do fazendeiro e de todos os grandes deste mundo. (REZENDE, 2015, p. 150)

Assis Tenório apresenta também o mundo masculino, que oprime o mundo feminino, cuja reação também se torna um dos fios narrativos. Típico disso é o acima referido episódio “O tempo em que dona Eulália foi feliz", que conta a história da mulher do político e latifundiário. Ele adoece de repente, de um mal misterioso, e vai tratar-se fora de Farinhada. Quem assume o comando é 
sua mulher, D. Eulália, a quem o povo passa a fazer pedidos. Pressionada, ela não só liberta os jagunços que, ao invés de aterrorizar os meeiros, reumanizam-se, como vai corrigindo outras formas de o marido oprimir o povo, unindo-se, inclusive, ao opositor de Assis Tenório, o Padre Franz:

Em poucos dias desabrochou na fazendeira uma coragem insuspeitada de fazer o que Ihe passasse pela cabeça e pelo coração, uma vontade de tudo resolver, ajeitar, melhorar, um desparramo de imaginação que fazia brotar ideias e mais ideias de como botar um final feliz a cada caso que Ihe aparecia. Mandou chamar Padre Franz, que veio, meio contrafeito, atravessando pela primeira vez a cancela de seu inimigo declarado, e com os conselhos dele estabeleceu um rol de melhorias para Farinhada e os sítios em redor, que mandou executar imediatamente. Reconstruíram-se escolinhas e capelas arruinadas, os jagunços feitos pacíficos pedreiros e carpinteiros, passou-se o trator pelas estrada da serra, abriu-se curso de corte e costura, distribuíram-se óculos de ver de perto e de ver de longe, deram-se cabras de raça prenhe para as mulheres grávidas, veio doutor, veio dentista, veio enfermeira da puericultura e finalmente, ó maravilha, Eulália mandou abrir as terras incultas da fazenda para quem quisesse botar roçado. (REZENDE, 2015, p. 75-76)

Outro caso, também um episódio, que mostra a mulher em luta contra a opressão é o de Aurora dos Prazeres, a quem, "contra todas as teorias, os manuais do sindicalismo e a tradição" se deveu, "em grande parte" (REZENDE, 2015, p. 125), o sucesso da greve no município de Cataventos.

O maravilhoso, presente em tantas epopeias, ocorre de certa forma em Vasto Mundo. É um maravilhoso baseado na religião, ao mesmo tempo budista e cristão. Assis Tenório, já bastante doente, é visto por um lama tibetano que conclui "Não é um mal que lhe fizeram, é o mal que ele mesmo fez" (REZENDE, 2015, p. 78). Seu laudo coincide com o da católica D. Otília, que à mesma hora conclui, dizendo a D. Eulália: "É peçonha, patroa, mas não de outro bicho, não, é a ruindade dele que não cabe mais lá dentro e está saindo pelo couro". E afirma que a única forma de cura é "desfazer todas as maldades que fez até hoje" (REZENDE, 2015, p. 79), receita aprovada pelo Padre Franz. Assis chega a dizer a D. Eulália: “Faça caridade, Lalá, faça muita caridade, faça todas as besteiras que você sempre quis fazer que eu pago tudo" (REZENDE, 2015, p. 80). Coroando esse episódio de caridade, de religação ao Bem, "pouco a pouco a inhaca esmoreceu, amanhou a comichão, foram secando e sumindo as feridas do corpo do deputado" (REZENDE, 2015, p. 80). 
Mais um elemento fez-nos sentir um sabor épico em Vasto Mundo: se os heróis das epopeias são marcados por seu amor ou por sua fidelidade às origens, como assinalou Rocha Pereira (2014, p. 335) entre os valores afetivos que arrola (lembremo-nos, por exemplo, dos esforços de Ulisses para voltar a Ítaca; do orgulho que navegantes de Os Lusíadas têm da pátria; ou ainda do trabalho de Martim a favor de Portugal), isso também ocorre no livro de Maria Valéria Rezende. Embora pobres, oprimidos, despossuídos mesmo, os homens e mulheres de Farinhada não a deixam de amar. É o caso, por exemplo, de Zefinha Lima, que a trocara pelo Rio de Janeiro, acompanhando o marido, mas que voltara, depois de vinte anos, quando ele morrera, caindo do sexto andar de uma construção. Zefinha quis morrer também, "já não pôde suportar mais o Rio de Janeiro [...] e comprou passagem para Itapagi. Os meninos ficavam; eram dali. Ela não, nunca fora, voltava para o seu chão" (REZENDE, 2015, p. 86)

Já se disse acima que o herói épico, diferente do herói trágico, não decide, mas, sim, os deuses, e que a epopeia escrita por cristãos, em tempos de conquista da terra brasileira, colocava Deus a auxiliar os portugueses. Diferente, mas que não deixa de estar nessa linha da épica é o que acontece em Vasto Mundo: não é Deus, mas o Padre Franz, representante da Igreja e da Teologia da Libertação, que se coloca ao lado do povo de Farinhada, na luta contra Assis Tenório, que envolveu contra essa gente os poderes locais e regionais, o Bispo y compris:

Na sexta-feira, a estratégia já estava armada. No sábado, Farinhada despertou com as pisadas que chegavam do povaréu que chegava de todos os sítios ao redor. Vinham de caminhão, montados ou a pé. Vieram os mais velhos ou as crianças, tão pequenas algumas, dentro dos caçuás no lombo dos jumentos. Aprígio chegou a galope, logo de manhãzinha, acompanhado de mais três cavaleiros, oferecendo-se para interceptar o cortejo do bispo lá para diante, bem antes que chegasse a Farinhada, mas Padre Franz o proibiu, 'só reze, Aprígio, reze que faz bem a você também!'. Aprígio obedeceu, mas foi engrossar o comitê popular que já tinha tomado em mãos outras rédeas, as dos acontecimentos. (REZENDE, 2015, p. 30)

E ainda mais uma coisa talvez nos tenha feito sentir o um sabor épico ao ler Vasto Mundo: o tempo cronológico ilimitado, de que nos fala Rocha Pereira e que acima citamos. Sem nenhuma referência a meses ou anos, num espaço onde convivem circo e televisão, contribuem para que a narrativa feita pela Voz do Chão opere essa abolição do datado, típica da epopeia. 


\section{Considerações Finais}

Diferentemente da epopeia dos tempos coloniais, onde portugueses lutavam contra os índios pela posse da terra, ou mesmo da epopeia romântica de Alencar, que abole o verso e apaga a rivalidade entre portugueses e indígenas para mostrar a fundação do Brasil como um ato de amor; ou ainda das epopeias do Modernismo, que valorizam a material mítica nacional, e mesmo das pós-modernas, Vasto Mundo narra, mais uma vez, a luta pela posse da terra. Dessa vez, porém, o herói é o povo subjugado pelos poderosos locais. Um povo que tem amor a Farinhada e que, em determinados momentos, embora breves, consegue lutar e vencer. Nessa busca da utopia, não se podem deixar de ver, embora de forma pontual, o maravilhoso, a decisão dos heróis, a abolição do datado, o amor à terra de nascimento, o auxílio não propriamente de Deus, mas da religião, o que confere à narrativa um sabor épico, mostrando-a como uma sobrevivência bastante diferente e fragmentada do gênero neste século XXI.

\section{Referências bibliográficas}

ALENCAR, José de. Iracema. Coimbra: Livraria Almedina, 1994.

ANCHIETA, Pe. Joseph de. S.J.. De gestis Mendi de Saa. Poema épico. São Paulo: Edições Loyola - Vice-Postulação da Causa de Canonização do Beato José de Anchieta, 1986 (trad. Armando Cardoso S.J.).

COSTA, Cláudio Manuel da. Vila Rica. In: PROENÇA FILHO, Domício (org). Poesia dos Inconfidentes. Poesia completa de Cláudio Manuel da Costa, Tomás Antônio Gonzaga e Alvarenga Peixoto. Rio de Janeiro: Nova Aguilar, 1996, p. 359-401.

LOBO, Luísa. "Conceito platônico de épica em Sousândrade". In: FRIEDLEN, Roger, NUNES, Marcos Machado, ZILBERMAN, Regina (Org). A epopeia em questão. Debates sobre a épica no século XIX. Rio de Janeiro: Ed. Makunaíma, 2020, p. 285-311.

PEREIRA, Maria Helena da Rocha. "O herói épico e o herói trágico". In: Estudos sobre a antiguidade clássica. Artigos. Lisboa/Coimbra: Fundação Calouste Gubenkian/Imprensa da Universidade de Coimbra, 2014, v.II, p. 311-328 (Obras de Maria Helena da Rocha Pereira).

PEREIRA, Maria Helena da Rocha. "Valores éticos na epopeia e na tragédia antiga". In: Estudos sobre a antiguidade clássica. Artigos. Lisboa/Coimbra: Fundação Calouste Gubenkian/Imprensa da Universidade de Coimbra, 2014, v.II, p. 336-346. (Obras de Maria Helena da Rocha Pereira).

REZENDE, Maria Valéria. Vasto mundo. Rio de Janeiro: Objetiva, 2015.

RIBEIRO, Maria Aparecida. "O rei morreu! Viva o rei! Magalhães, Alencar e o fim da epopeia no Brasil”. In: FRIEDLEN, Roger; NUNES, Marcos Machado; ZILBERMAN, Regina (Org). A epopeia em questão. Debates sobre a épica no século XIX. Rio de Janeiro: Ed. Makunaíma, 2020, p. 173-200. 
SOUSÂNDRADE, J. de. "Memorabilia". In: MORAES, Jomar; WILLIAMS, Frederick G. (org.). Poesia e prosa reunidas de Sousândrade, 2003. p. 484-487. Prefácio a Guesa errante, publicado em Nova York em 1876, p. I a V. 